hyperthyroid patients and observed no change in serum $\mathrm{T} 3$ concentrations. $^{2}$ We realise that these $\beta$-adrenergic blocking drugs are less active than propranolol as membrane-stabilising agents, both as a local anaesthetic and in their action on intracellular cardiac potentials, ${ }^{3}{ }^{4}$ but we would have expected to see a fall in serum T3 levels if the mechanism proposed by $\mathrm{Dr}$ Heyma and others is correct. Further information on this point, in particular from the study of hyperthyroid patients, is obviously required.

$\mathrm{M} \mathrm{K}$ JONES

G R JONES

J BIRTWELI

Department of Medicine,
University Hospital of Wales,
Cardiff CF4 4XW

${ }^{1}$ Nilsson OR, Karlberg BE, Kag̊edal B, Tegler L, Almqvist S. Acta Med Scand 1979;206:21-5.

2 Jones MK, John R, Jones GR. Clin Endocrinol (in 3 press).

1970; - Williams

Pharmacol 1973;48:198-211.

\section{Febrile seizures}

SIR,-The "consensus statement" of The National Institutes of Health (NIH) about febrile seizures (26 July, p 277) is remarkable among writings on this subject because of its clarity. Nevertheless in their answer to the question "Which children should be considered for prophylaxis ?" the authors appear to be guilty of muddled reasoning.

They list as reasons for anticonvulsant prophylaxis those conditions which might presage the later development of epilepsy-that is, abnormal neurological findings, prolonged or focal convulsions, or a family history of epilepsy in a first-degree relative. This seems at odds with their statement (in italics) that "There is no evidence to support the concept that prolonged therapy with anticonvulsants prevents the development of epilepsy or significant neurological deficits." If, as they say, anticonvulsant prophylaxis prevents only subsequent febrile convulsions then surely the indications for such treatment should be those factors which are associated with a high risk of recurrent febrile convulsions (such as age less than 18 months) and not those associated with a higher risk of later developing epilepsy (all of which are unalterable by the time the decision about prophylaxis comes to be made). Most articles of the past 10-15 years on the use of anticonvulsant prophylaxis after febrile convulsions have emphasised the risk of subsequent epilepsy or neurological damage. It now seems, however, that such risk is small and unlikely to be greatly influenced by giving anticonvulsants. ${ }^{1}$

The equation to be balanced is now, therefore, much simpler: on the one side the likelihood and undesirability of further febrile convulsions, and on the other the risks of long-term prophylaxis as outlined by the $\mathrm{NIH}$ panel. In most instances, the right-hand side of this equation might be felt to be the more weighty but on occasions, such as with a very young child or when parental anxiety is unusually high, the risks of therapy might be thought to be worth while.

D P ADDY

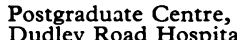

Dudley Road Hospital

${ }^{1}$ Nelson KB, Ellenberg JH. Pediatrics 1978;61:720-7.

\section{Convulsions associated with} campylobacter enteritis

SIR,-The occurrence of convulsions in several children during an epidemic of campylobacter enteritis reported by $\mathrm{Dr} S$ Havalad and others (5 April, p 984) prompts us to report two further cases admitted to a general paediatric ward in the last two years.

A 14-month-old boy with no previous history of fits had a generalised convulsion lasting 20 minutes. He had felt hot the day before and on admission his temperature was $40^{\circ} \mathrm{C}$. There was slight rhinorrhoea but no other clinical abnormality. A cerebrospinal fluid examination showed normal biochemical values, no cells, and no bacterial growth. Symptomatic treatment with phenobarbitone, paracetamol, and cooling was commenced. Twelve hours later bulky and offensive stools, without blood or mucus, were passed and these and a rectal swab taken on admission yielded Campylobacter jejuni-coli. There was no vomiting and he recovered within four days with no additional therapy.

A 4-year-old girl was admitted following a generalised convulsion lasting 10 minutes, which was associated with several episodes of vomiting and diarrhoea. She had never had a fit before. Her temperature was $37 \cdot 7^{\circ} \mathrm{C}$ and there was still some twitching of the limbs on admission. A cerebrospinal fluid examination was normal but $C$ jejunicoli was isolated from a rectal swab. Like the previous child she recovered within four days with symptomatic treatment. $C$ jejuni-coli was subsequently isolated from faeces of the patient's 6-yearold sister, who had no symptoms.

In the last two years $C j e j u n i$-coli was found in only two other children (one with croup and one with vomiting) from a total of approximately 1300 who had a routine rectal swab examined on admission. About a quarter of these were admitted following a fit, so in this small series the association between fits and admission to hospital with campylobacter enteritis was no greater than expected by chance.

Campylobacter infection appears to be an uncommon cause of febrile convulsions but the experience of Dr Havalad and his colleagues and our own reported here indicate that it should be considered as a possible cause in children whose convulsion is associated with diarrhoea.

E P WRIGHT

Public Health Laboratory, Fazakerley Hospital,

\section{Birkenhead Children's Hospital,}

JOHN SEAGER

\section{Aminocaproic acid myopathy}

SIR,-The report by Dr C K Biswas and others (12 July, $p$ 115) of an acute necrotising myopathy occurring during treatment with aminocaproic acid, together with other reports of this complication, ${ }^{1}$ raises doubts about the safety of this form of treatment in patients with subarachnoid bleeding and in other conditions.

We have now had experience of two cases. In both recovery was complete when the drug was withdrawn. The pathogenesis of the disorder is uncertain, but our studies suggested that microvascular thrombosis may play a part. ${ }^{1}$ Attempts, however, to induce the myopathy experimentally in the rat failed, even when doses several times larger than those given to patients were used. The myopathy seems to occur in patients in whom the drug has been given for longer than about a month, and in most cases the interval between starting the drug and the development of myopathy has been longer than this. The optimal duration of therapy in patients with subarachnoid bleeding is uncertain, but experience with this complication suggests that other fibrinolytic agents, such as tranexamic acid, may perhaps be free of this serious complication.

Michael Swash

Neurology Department,

The London Hospital

${ }^{1}$ Kennard C, Swash M, Henson RA. Myopathy due to amino caproic acid. Muscle and Nerve 1980;3:202-6.

\section{Adverse reactions to $\mathrm{D}$-penicillamine} after gold toxicity

SIR,-Dr M J Dodd and others (21 June, $p$ 1498) provided two explanations for the findings in their interesting paper. They suggested that patients who develop side effects from D-penicillamine after demonstrating toxicity to gold salts may do so either because the former drug results in mobilisation of gold from tissue stores or because patients develop cross-reactivity to the thiol component common to both drugs. A third possibility should be considered: susceptibility to drug toxicity may relate to genetic status ${ }^{1-3}$ and thus patients who develop side effects from one drug may be at risk from another.

ANDREi Calin

Department of Medicine,

Stanford University Medical Center,

年,

${ }^{1}$ Panayi GS, Wooley P, Batchelor JR. Br Med f 1978

${ }^{2}$ Bi: 1 1326-8. Batchelor JR, Welsh KI, Tinoco RM, et al. Lance
1980;i:1107-9.

\section{Following up patients with rheumatoid} arthritis

SIR,-Your recent leading article (12 July, p 97) on the continuing care of people with rheumatoid arthritis makes dismal reading. The rheumatologist will contribute his expertise. He cannot, however, offer much in the way of personal support, except at moment of crisis. His junior staff and ancillary workers are bound, in the nature of things, to change at fairly frequent intervals with consequent loss of continuity.

The general practitioner must necessarily be involved, and the care of the chronic sick is one of his acknowledged responsibilities. You mention epidemiological evidence of the prevalence of this disease. It follows that general practitioners do, in fact, gain considerable familiarity with both its manifestations and its treatment.

Could we not co-operate more? The rheumatologist may know that certain practices are more ready than others to shoulder this particular responsibility. If he is in doubt, could he not ask ? It is important also that in providing intensive involvement early in the course of the disease hospitals do not undermine confidence in the patient's doctor. Lastly, there is a great need for vocational trainees to acquire experience in rheumatology.

David G Williams

Aylsham,
Norfolk NR11 6EH 